\title{
The incidence of HLA-SD antigens in recessive retinitis pigmentosa
}

\author{
MELVIN C. CHEN, GEORGE E. MARAK, AND A. RAYMOND PILKERTON \\ From the Department of Ophthalmology, Georgetown University Medical Center, Washington, DC, USA
}

SUMMARY Eighteen patients with recessive retinitis pigmentosa were tissue typed for HLA-SD antigens. There was no evidence that a particular HLA-SD antigen was associated with autosomal recessive retinitis pigmentosa.

Retinitis pigmentosa is a disease of unknown aetiology characterised by slowly progressive night blindness, contracted visual fields, and visual loss. One of the many theories on the pathogenesis of this disease is that autoimmunity may be involved. Indirect evidence such as the electroretinogram (ERG) changes associated with allergic reactions to retinal antigens (MacDonald, 1971; Rahi et al., 1976) the association of the disease with elevated IgM levels (Rahi and Garner, 1976), and evidence of cell mediated immunity in pigmentary retinal degeneration (Char et al., 1974) suggest the possibility of an autoimmune component in the pathogenesis of retinitis pigmentosa. In a number of diseases with autoimmune components an increased incidence with particular HLA-SD antigens has been found (Ritzmann, 1976). The purpose of the present study is to determine if there is any associated HLA-SD antigen in patients with retinitis pigmentosa of the recessive type.

\section{Patients and methods}

Eighteen patients with retinitis pigmentosa, 8 males and 10 females ranging from the ages of 12 to 80 years, were tissue typed for HLA-SD antigens. All the patients with the exception of the 12-year-old child had severely contracted visual fields and visual loss. Patients who were not blind had night blindness, and all had been evaluated at more than one eye institution and diagnosed as having retinitis pigmentosa.

All the patients in this study were registered with the Retinitis Pigmentosa Foundation, and a careful examination of their families showed each case to

Address for reprints: Dr A. Raymond Pilkerton, Department of Ophthalmology, Georgetown University Medical Center, 3800 Reservoir Road, NW, Washington, DC 20007, USA be of the autosomal recessive type. In no case did the disease occur in the prior 2 generations of each proband. Further, in 13 of the cases the patient was the only one in the family affected. In the remaining 5 cases, 4 had a sibling of the opposite sex affected, and in the fifth case 2 brothers were affected. In the last case there were no cases of retinitis pigmentosa in any children of the parents' siblings.

The control population consisted of the average HLA-SD frequencies from both the April 1976 American workshop on tissue typing (Mickey, 1976) and current laboratory data.

The method used for tissue typing was the modified Amos procedure (Amos, 1977).

\section{Results}

The results of this study appear in Table 1 . The HLA-SD antigens which appeared with the highest frequency in the test population were HLA-A2, HLA-A3, HLA-B7, and HLA-B12. HLA-A9-W23 and HLA-AW29 did not occur in any of the patients tested. Probability was calculated by the chi-squared test with Yeats's correction. At the significance level of $5 \%$ the frequency of HLA-SD antigen in the patients with retinitis pigmentosa was no greater than in the control population.

\section{Conclusion and discussion}

This study failed to reveal an association between a particular HLA-SD antigen and retinitis pigmentosa. It may be that an association was not found because a different HLA-SD antigen (determined by serological tests) in different ancestries is associated with retinitis pigmentosa, and that the control data on HLA-SD antigen frequencies must be further broken down according to ancestry. The possibilities 
Table 1 Frequency of $H L A-S D$ antigens in retinitis pigmentosa

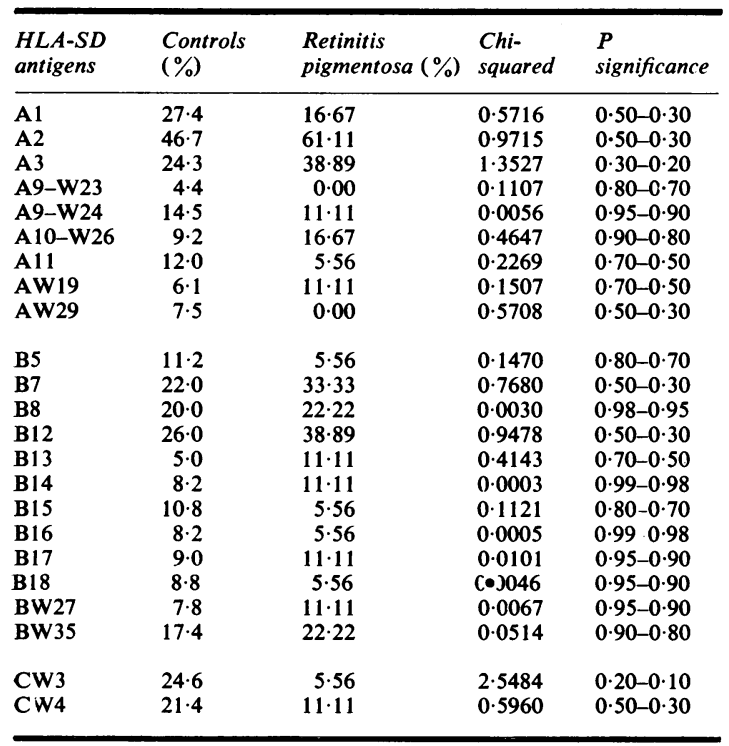

also exist that the HLA-SD antigen sought has not yet been identified or that the association may be with an HLA-LD antigen (determined by mixed lymphocyte reaction) (Bach and van Rood, 1976), which would further explain why no association could be established.

The evidence that an autoimmune component may be involved in the pathogenesis of retinitis pigmentosa remains indirect. In the absence of unequivocal histopathological evidence of inflammation an autoimmune component as a possible cause of retinitis pigmentosa remains unsupported. The observation that retinitis pigmentosa fails to be associated with an atypical distribution of HLA-SD antigens does not provide any additional support to the theory that autoimmunity is involved in the pathogenesis of the disease.

Acknowledgement is made to the Retinitis Pigmentosa Foundation, Washington, DC, Chapter for recruiting patients for this study.

This study was funded in part by the National Eye Institute Grant EY00887-06.

\section{References}

Amos, D. B. (1977). NAID Manual of Tissue Typing Techniques, Department of Health, Education and Welfare, Bethesda, Maryland

Bach, F. A., and Van Rood, J. J. (1976). The Major Histocompatibility Complex-Genetic and Biology, New England Journal of Medicine, 295, 806-813, 872-878, 927-936.

Char, D. H., Bergsma, D., Rabson, A. S., Albert, D. M. and Herberman, R. B. (1974). Cell-mediated Immunity to Retinal Antigens in Patients with Pigmentary Retinal Degenerations, Investigative Ophthalmology, 13, 198-203.

MacDonald, F. (1971). Correlated Studies on Experimental Allergic Uveo-Retinal Disease, Transactions of the American Ophthalmological Society, 69, 397-439.

Mickey, R. M. (1976). HLA Workshop of the Americas, Bureau of Biologics, Bethesda, Maryland.

Rahi, A. H. S., and Garner, A. (1976). Immunopathy of the Eye, 1st edn. Blackwell Scientific Publications: Oxford.

Rahi, A. H. S., Lucus, D. R., and Waghe, M. (1976). Experimental Immune Retinitis: Induction by Isolated Photoreceptors, Modern Problems in OphthalmologyOcular Immune Responses, 16, 30-40.

Ritzmann, S. E. (1976). HLA Patterns and Disease Associations, Journal of the American Medical Association, 236, 2305-2309. 